\title{
The roles of anion and solvent transport during the redox switching process at a poly(butyl viologen) film studied by an EQCM
}

\author{
Chih-Yu Hsu ${ }^{\mathrm{a}}$, Chun-Hao Liao ${ }^{\mathrm{a}}$, Kuo-Chuan $\mathrm{Ho}^{\mathrm{a}, \mathrm{b}, *}$ \\ ${ }^{a}$ Department of Chemical Engineering, National Taiwan University, Taipei 10617, Taiwan \\ ${ }^{\mathrm{b}}$ Institute of Polymer Science and Engineering, National Taiwan University, Taipei 10617, Taiwan
}

Received 27 September 2006; received in revised form 23 May 2007; accepted 31 May 2007

Available online 24 September 2007

\begin{abstract}
In this study, three electrolytes $\left(\mathrm{KCl}, \mathrm{LiCl}\right.$, and $\mathrm{KNO}_{3}$, each at $0.5 \mathrm{M}$ in aqueous solution) were chosen to study the ion and solvent effect on the redox performance of poly(butyl viologen) (PBV) thin-films between its di-cation and radical-cation state, which is referred as its first redox couple. Before considering the role of ionic transport on the redox process, the exchange between ferrocyanide and anion should be completed. Since the deposition solution of PBV contains potassium ferrocyanide, the residual ferrocyanides inside the films would be exchanged by smaller anions from the bulk solution during the redox reaction of PBV. From cyclic voltammetry (CV) and electrochemical quartz crystal microbalance (EQCM) results, the exchange was almost complete around 50 cycles when scanning the potential within its first redox range. After completion of the exchange process, the transfer would reach a steady state. At 50 cycles, the EQCM results suggested that the transport involves anions and water only for both being extracted upon reduction and being inserted upon oxidation. Therefore, we could obtain the molar fluxes of $\mathrm{Cl}^{-}, \mathrm{NO}_{3}{ }^{-}$, and water. Besides, the average numbers of accompanying water were calculated to be about 24.8 per $\mathrm{Cl}^{-}$and 14.2 per $\mathrm{NO}_{3}{ }^{-}$upon redox switching process. The instantaneous water to anion molar ratios at any potential were also obtained for $\mathrm{Cl}^{-}$and $\mathrm{NO}_{3}{ }^{-}$.
\end{abstract}

(C) 2007 Elsevier B.V. All rights reserved.

Keywords: Anion transport; Electrochemical quartz crystal microbalance (EQCM); Ion exchange; Molar flux; Poly(butyl viologen)

\section{Introduction}

When exerting a bias on an electroactive thin-film, the accompanying redox process results in the valence change of the material. Meanwhile, ions would transport into the film to maintain the electroneutrality condition. In most cases, transports of neutral salt and solvent are also involved. The stoichiometry of the transport during redox process would be affected by the sort of salts and the morphology of films.

Viologens, namely $1,1^{\prime}$-disubstituted-4,4'-bipyridinium salts, have successfully been prepared as a surface-confined electrode by electropolymerization method [1-3]. Upon redox reaction, polyviologens $(\mathrm{PV})$ can switch among di-

\footnotetext{
${ }^{*}$ Corresponding author. Department of Chemical Engineering, National Taiwan University, Taipei 10617, Taiwan. Tel.: + 886223660739 ; fax: +886223623040 .

E-mail address: kcho@ntu.edu.tw (K.-C. Ho).
}

cation $\left(\mathrm{PV}^{2+}\right)$, radical-cation $\left(\mathrm{PV}^{\bullet+}\right)$, and di-reduced states $\left(\mathrm{PV}^{0}\right)$ with obvious changes in the visible absorption spectra concomitantly. Furthermore, the successive reversible redox behavior of the PV showed that they could be used as an electrochromic material in the switchable devices [4]. While most studies of viologens have focused on the first redox couple $\left(\mathrm{V}^{2+} \leftrightarrow \mathrm{V}^{\bullet+}\right)$ for its highly reversible property without significant side reactions [5]. Therefore, in order to quantitatively realize the movement of ions and solvent involving in a PV film during the first redox switching, it is essential to monitor the in-situ mass change. Cyclic voltammetry (CV) and electrochemical quartz crystal microbalance (EQCM) techniques fulfill this requirement to probe the transport of ions and solvent during the redox process. By employing resonance on a quartz crystal, it is practicable to obtain small mass changes at the thin-film from the changes in the resonant frequency of the resonator [6]. These techniques had been used to study the redox behavior of 
viologen monolayers formed by the self-assembly process [7-10].

In the case of polycationic films, such as PV in aqueous solutions, it is certain that the amounts of chargecompensating monovalent counterions, i.e., anions, would be as high as the amounts of redox sites. Consequently, the as-deposited films would contain counterion from the deposition solution. However, if the ionic species present in the electrolyte solution are different from that in the deposition solution, the ion exchange process within the film would take place, which was observed in our previous work [3]. This behavior has also been noticed for polypyrole films $[11,12]$. It is found that the exchange process depends on the ion size [11], and a larger ion would be probably replaced by a smaller one. Moreover, the concentration difference between the counterions incorporated within the film and the ions in the electrolyte solution would definitely be another driving force for the exchange process.

In this work, a poly(butyl viologen) (PBV) thin-film was electropolymerized from its monomer, bis(4-cyano-1-pyridino)butane dibromide. Since the deposition solution contains ferrocyanide anion, the electrolytic solution for further characterization of the films should contain salts with different anions. Besides, the PBV film would shrink in organic solutions due to its hydrophilic nature [3]. The film is also unstable in acid environment due to its catalytic nature of radical cation of viologen species, which is easy to react with protons [13]. Therefore, the objective is to elucidate the behavior of anion exchange at a PBV film in neutral aqueous solution within its first redox range, as shown in Scheme 1, using CV and EQCM analyses. After the exchange process is completed, the ion transport should
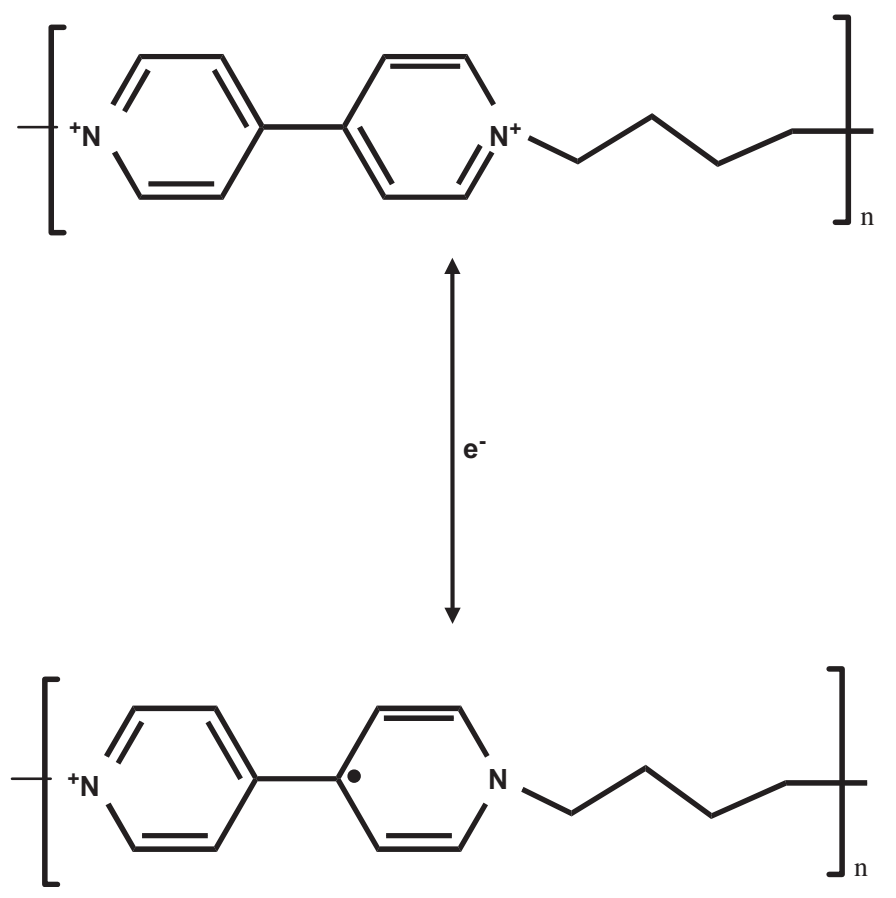

Scheme 1. reach a steady state. The roles of anion and solvent transport under different anionic conditions would also be identified to realize the transport phenomena during the redox switching process of PBV films.

\section{Experimental}

\subsection{Preparation of $P B V$ thin films}

All chemicals were ACS reagent grade and used without further purification. All aqueous solutions were made with deionized water (DIW) of resistivity about $18.2 \mathrm{M} \Omega-\mathrm{cm}$. Experiments were all performed at room temperature $\left(25 \pm 2{ }^{\circ} \mathrm{C}\right)$ and in air.

Before the CV and EQCM analyses, the PBV thinfilms were potentiostatically electropolymerized from bis (4-cyano-1-pyridino)butane dibromide $\left(\mathrm{BVBr}_{2}\right)$. Electropolymerization was performed on $0.196 \mathrm{~cm}^{2}$ platinum electrode coated on the AT-cut quartz crystals with $9 \mathrm{MHz}$ (Seiko $\mathrm{EG} \& \mathrm{G}) . \mathrm{BVBr}_{2}$ was synthesized by a method described in a previous study [3]. The bath solution contained $20 \mathrm{mM}$ $\mathrm{BVBr}_{2}, 10 \mathrm{mM} \mathrm{K \textrm {K } _ { 2 }} \mathrm{PO}_{4}, 90 \mathrm{mM} \mathrm{K} \mathrm{KPO}_{4}$, and $100 \mathrm{mM}$ $\mathrm{K}_{4} \mathrm{Fe}(\mathrm{CN})_{6}$. The PBV thin-films were deposited onto the electrode at a constant potential of $-0.75 \mathrm{~V}$ (vs. $\mathrm{Ag} / \mathrm{AgCl} /$ sat'd $\mathrm{KCl}$ ) until a charge capacity of $100 \mathrm{mC} / \mathrm{cm}^{2}$ was reached and then stepping to $0 \mathrm{~V}$ for $180 \mathrm{~s}$. After PBV films were formed, they were washed with DIW to remove the residual bath solutions and stored in air.

\subsection{Apparatus}

The ion exchange and transport behaviors of the PBV thin-films were characterized in aerated $0.5 \mathrm{M}$ aqueous solutions of three different electrolytes $(\mathrm{KCl}, \mathrm{LiCl}$, and $\mathrm{KNO}_{3}$ ) using potentiostat/galvanostat (Autolab, model PGSTAT30) for $\mathrm{CV}$ measurements and quartz crystal analyzer (Seiko EG\&G, model QCA917) for in situ EQCM measurements. The electrochemical experiments being carried out in a three-electrode system, a platinum sheet $(4.0 \times 1.0 \mathrm{~cm})$ was used as a counter electrode and a homemade $\mathrm{Ag} / \mathrm{AgCl} /$ sat'd $\mathrm{KCl}$ was used as a reference electrode. All potentials reported in the following are relative to the $\mathrm{Ag} / \mathrm{AgCl} / \mathrm{sat}$ 'd $\mathrm{KCl}$ electrode. $\mathrm{PBV}$-modified platinum electrode on the quartz crystal was used as the working electrode. The working electrode enclosed by a Teflon holder and sealed against the solution using O-rings to prevent one side contact from the solution.

\section{Results and discussion}

\subsection{Ion exchange}

Fig. 1 shows the CVs of a PBV film scans for 100 cycles in a $\mathrm{KCl}$ solution and a $\mathrm{KNO}_{3}$ solution. In Fig. 1(a), a PBV film was switched within its first redox range in a $\mathrm{KCl}$ solution, namely $\mathrm{PBV}^{2+} / \mathrm{PBV}^{\bullet+}$ between 0 and $-0.8 \mathrm{~V}$, the corresponding peak current densities $\left(J_{\mathrm{p} 1}^{\mathrm{a}}, J_{\mathrm{p} 1}^{\mathrm{c}}\right)$ still 
a

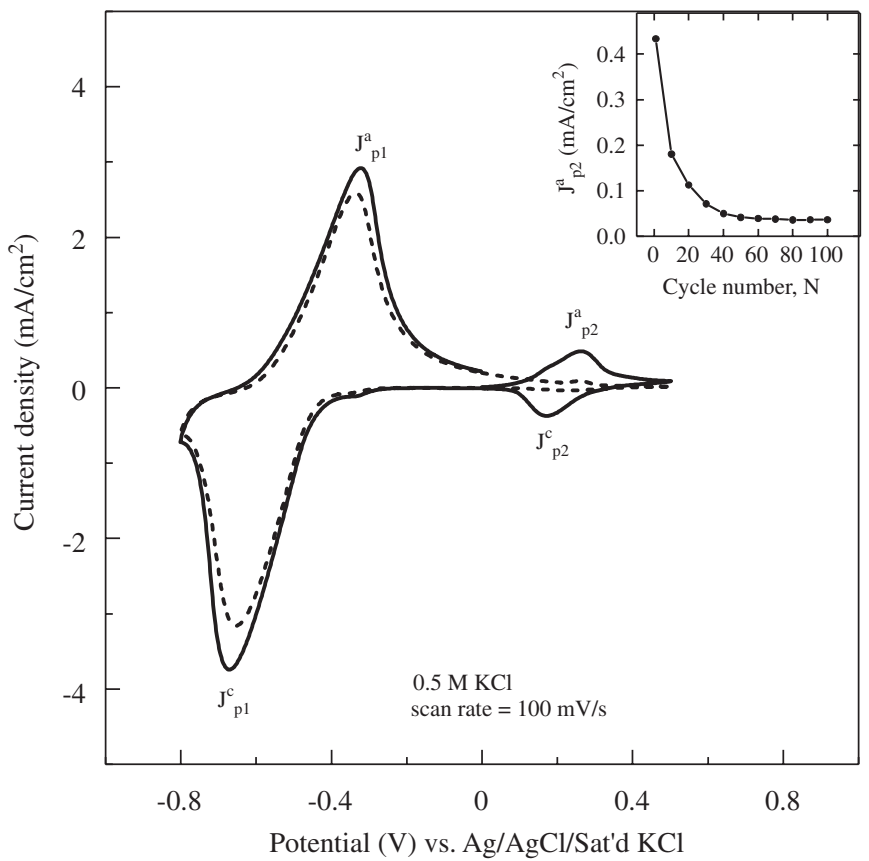

b

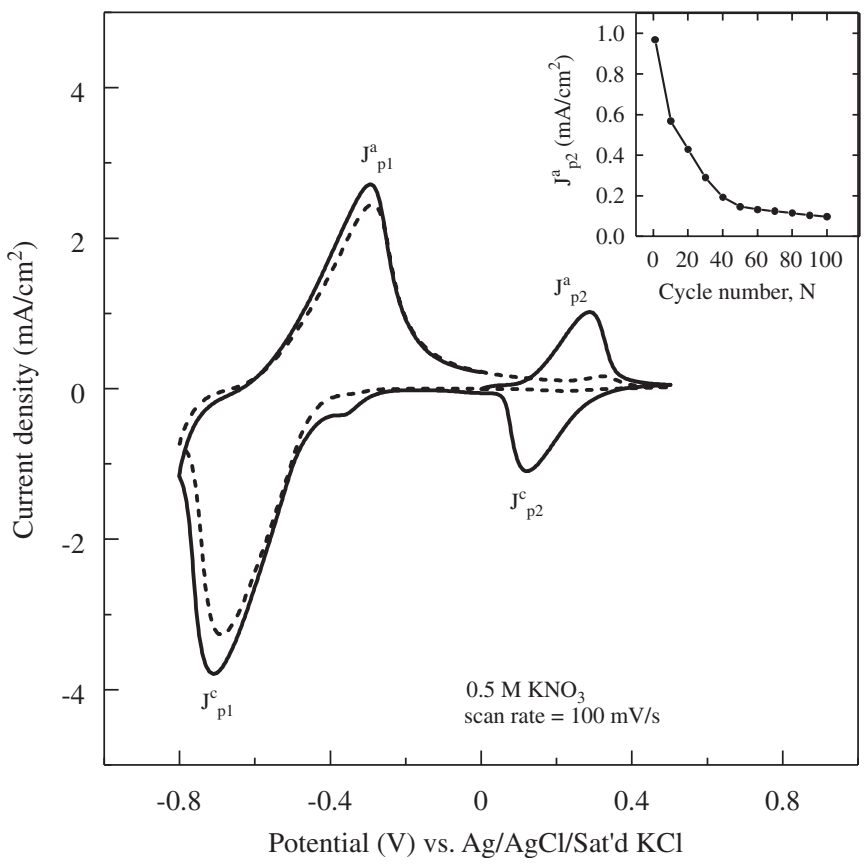

Fig. 1. Cyclic voltammograms of a PBV film scanning for 100 cycles (, 1st cycle; - . - - , 100th cycle) in (a) a $0.5 \mathrm{M} \mathrm{KCl}$ solution and (b) a $0.5 \mathrm{M}$ $\mathrm{KNO}_{3}$ solution at a scan rate of $100 \mathrm{mV} / \mathrm{s}$. The insets show the second anodic peak current density as a function of the cycle number.

remained $88 \%$ of its initial value after 100 cycles. Another electrochemical reaction involving residual ions inside the PBV film at more positive potential higher than $0 \mathrm{~V}$, and the corresponding peak current densities $\left(J_{\mathrm{p} 2}^{\mathrm{a}}, J_{\mathrm{p} 2}^{\mathrm{c}}\right)$ has to do with the reaction between $\mathrm{Fe}(\mathrm{CN})_{6}^{4-}$ and $\mathrm{Fe}(\mathrm{CN})_{6}^{3-}$. The ferrocyanide anions were incorporated into the PBV film during electropolymerization process in order to electroneutralize the positively charged PBV molecules. According to the inset of Fig. 1(a), the anodic peak current density for the oxidation of ferrocyanides $\left(J_{\mathrm{p} 2}^{\mathrm{a}}\right)$ decreased with the cycle number and only remained about $8 \%$ of its initial value after 100 cycles. Comparing with the first redox couple of PBV, the severe decay is resulted from the anion exchange, which means that the residual ferrocyanide anions inside the film would be replaced by smaller anions from the bulk solution during the redox switching, i.e., $\mathrm{Cl}^{-}$in this case. The ionic size of $\mathrm{Cl}^{-}$is smaller than that of $\mathrm{Fe}(\mathrm{CN})_{6}^{4-}$, regardless of crystal radii or hydrated radii [14]. Besides, for different anions such as $\mathrm{NO}_{3}^{-}$in later discussion, the ionic exchange was also observed and it also took 50 cycles to complete, as shown in Fig. 1(b). The ion exchange in a $\mathrm{KNO}_{3}$ solution was also significant for the first 50 cycles and became steady after 50 cycles. Consequently, the exchange process by either $\mathrm{Cl}^{-}$or $\mathrm{NO}_{3}^{-}$is similar. If the size of the anion from the bulk solution is too large, such as $\mathrm{LiN}\left(\mathrm{CF}_{3} \mathrm{NO}_{3}\right)_{2}$, the film would be damaged while transporting the large anion in and out of the film, thus reducing its electrochemical stability (not shown here). Therefore, we only considered $\mathrm{Cl}^{-}$and $\mathrm{NO}_{3}^{-}$due to their smaller ionic sizes, which are easier for the ion exchange and ion transport.

From the inset of Fig. 1(a), the ion exchange process was almost complete around 50 cycles, and the results are also supported by an EQCM analysis by monitoring the mass changes in the PBV film during a CV scan. The mass changes were converted from the frequency changes of the quartz crystal resonator by using Sauerbrey equation [15]:

$\Delta m=\Delta f \frac{A \sqrt{\mu_{\mathrm{q}} \rho_{\mathrm{q}}}}{-2 f_{0}^{2}}$,

where $f_{0}$ is the resonant frequency of the fundamental mode of the crystal, $A$ is the surface area of the Pt electrode on the crystal $\left(0.196 \mathrm{~cm}^{2}\right), \mu_{\mathrm{q}}$ is the shear modulus of ATcut quartz $\left(2.947 \times 10^{11} \mathrm{~g} \mathrm{~cm}^{-1} \mathrm{~s}^{-2}\right)$, and $\rho_{\mathrm{q}}$ is the density of quartz $\left(2.648 \mathrm{~g} \mathrm{~cm}^{-3}\right)$. The in situ mass changes measured at various $\mathrm{CV}$ scans for the first redox couple of PBV are shown in Fig. 2. For the 1st cycle, the final value of the mass change did not match with that of the initial value. Therefore, it is understood that the ionic insertion and extraction, which are mass-sensitive, had not reached a steady state at the end of the 1st cycle. On the contrary, the mass changes were nearly steady at the 10th, 50th, and 60th cycles. Moreover, for consecutive aspect, the entire curves of mass change from the 1st cycle to the 50th cycle were shifted positively. For that from the 50th cycle to the 60th cycle, however, the two curves were closely overlapped. The first 10 cycles showed poor reversibility in term of ionic transport, however, the ion exchange between $\mathrm{Fe}(\mathrm{CN})_{6}^{4-}$ and $\mathrm{Cl}^{-}$was almost complete around 50 cycles. The result obtained from the mass analysis is in good agreement with the CV observed.

The ionic transport would reach a steady state when the ion exchange process is completed. Accordingly, the PBV 


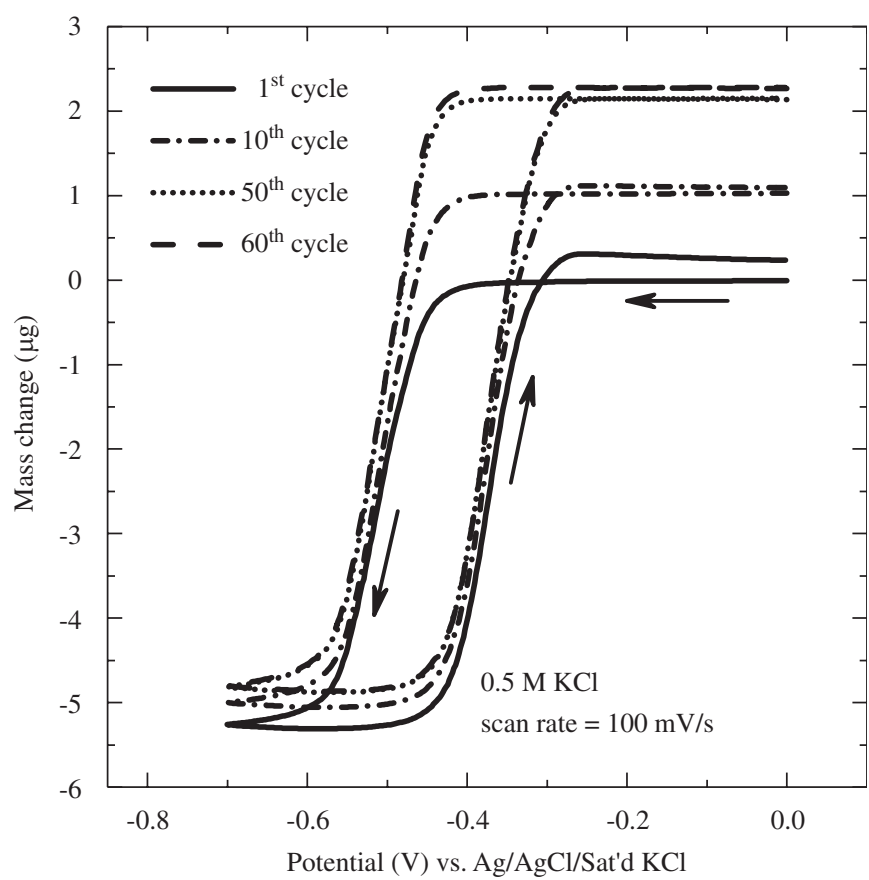

Fig. 2. The in situ mass change of a PBV film as CV scanning within its first redox range $(0$ to $-0.7 \mathrm{~V})$ for the 1 st (-), 10th $(-\cdot-)$, 50th $(\ldots \ldots)$, and 60 th $(-\cdots)$ cycles in a $0.5 \mathrm{M} \mathrm{KCl}$ solution at a scan rate of $100 \mathrm{mV} / \mathrm{s}$.

film should be scanned upon electrochemical cycling to allow the exchange between ferrocyanide and anion and then consider the steady-state ionic transport of the redox process. The steady-state ionic transport process can thus be studied with $\mathrm{Cl}^{-}$or $\mathrm{NO}_{3}^{-}$upon the completion of ion exchange that contains no $\mathrm{Fe}(\mathrm{CN})_{6}^{4-}$. In addition, it is very likely that the structure of the PBV polymer chain changes after the ion exchange due to different electro-attractive forces which exist between large $\mathrm{Fe}(\mathrm{CN})_{6}^{4-}$ and small $\mathrm{Cl}^{-}$ or $\mathrm{NO}_{3}^{-}$. However, the film remained stable electrochemically after the ion exchange despite the possible structural change of the polymer chain. Thus, as long as the morphology of the film is not damaged after the ion exchange, it is possible to observe the ion transport phenomena noted in Section 3.3.

\subsection{Anion effect}

When the exchange between residual ferrocyanides inside the PBV film and the anions from the bulk solution was complete, subsequent insertion and extraction of ions would show the intrinsic characteristics. However, the transportation involves cations, anions, and solvent, and each might play a part in mass contribution. Fig. 3 shows the mass change against the accumulated charge at the 50th cycle in different electrolyte solutions. The apparent mass change characteristics for $\mathrm{KCl}$ were similar to that for $\mathrm{LiCl}$, but both were totally different from that for $\mathrm{KNO}_{3}$. Therefore, cations would not affect the macro-phenomenon of ion transport but anions play an important role. It is

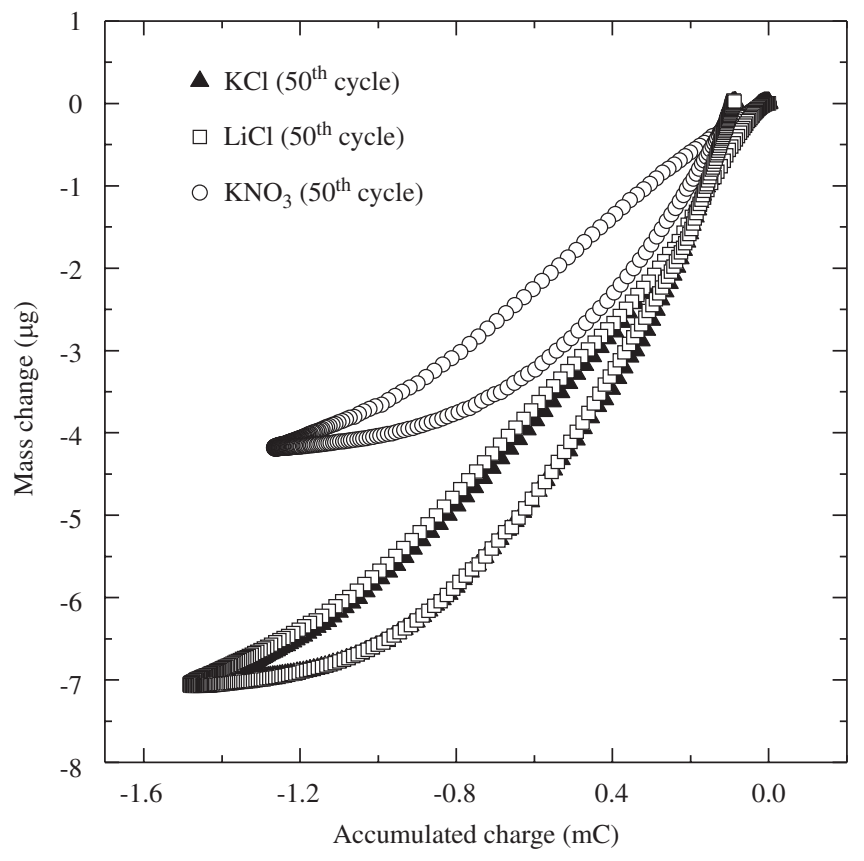

Fig. 3. Comparisons of the mass-charge relationship for PBV films obtained from the 50th $\mathrm{CV}$ cycle within the potential range from 0 to $-0.7 \mathrm{~V}$ at a scan rate of $100 \mathrm{mV} / \mathrm{s}$ in $0.5 \mathrm{M} \mathrm{KCl}(\mathbf{\Delta}), \mathrm{LiCl}(\square)$, and $\mathrm{KNO}_{3}$ ( $\bigcirc)$ solution.

generally accepted that the reaction of the first redox couple for a polyviologen film is limited by the diffusioncontrolled process [16], so the charge compensation from the counterions, i.e., anions, should be the dominant species during the electrochemical reaction for such polycationic films. In addition, Ock et al. also inferred that cations might not easily diffuse into the viologen monolayer because of its alkyl chain [10]. Since PBV molecule also has a butyl group, it is reasonable to neglect the effect of cations but to consider that of anions only. Thus, the steady-state first redox reaction for a PBV film switched in aqueous electrolyte containing different anions can be generally written by the following equation, which is in agreement with our previous results [3]

$\left[\mathrm{PBV}^{2+} X_{2}^{-}\right]+\mathrm{e}^{-} \rightleftharpoons\left[\mathrm{PBV}^{\bullet+} X^{-}\right]+X^{-}$

where $\mathrm{X}^{-}$represents anions, such as $\mathrm{Cl}^{-}$or $\mathrm{NO}_{3}^{-}$, in this study.

Since anion is the dominant species for the redox reaction, it does influence the electrochemical behavior of the PBV film, as shown in Fig. 4. The CV curves obtained at the 50th cycle, for both $\mathrm{Cl}^{-}$and $\mathrm{NO}_{3}^{-}$, were different. For viologen monolayer, it was found that the voltammetric response scans within its first redox range is also anion dependent [17]. The peak separation of $\mathrm{CV}$ curves for $\mathrm{NO}_{3}^{-}$ is larger than that of $\mathrm{Cl}^{-}$as observed in Fig. 4. The smaller the peak separation indicates the less the reaction resistance. Moreover, from the anion's size perspective, $\mathrm{Cl}^{-}(1.81 \AA)$ has smaller ionic radii than that of $\mathrm{NO}_{3}^{-}$ (2.64 $\mathrm{\AA})[14]$. Therefore, this implies that the larger anion is 


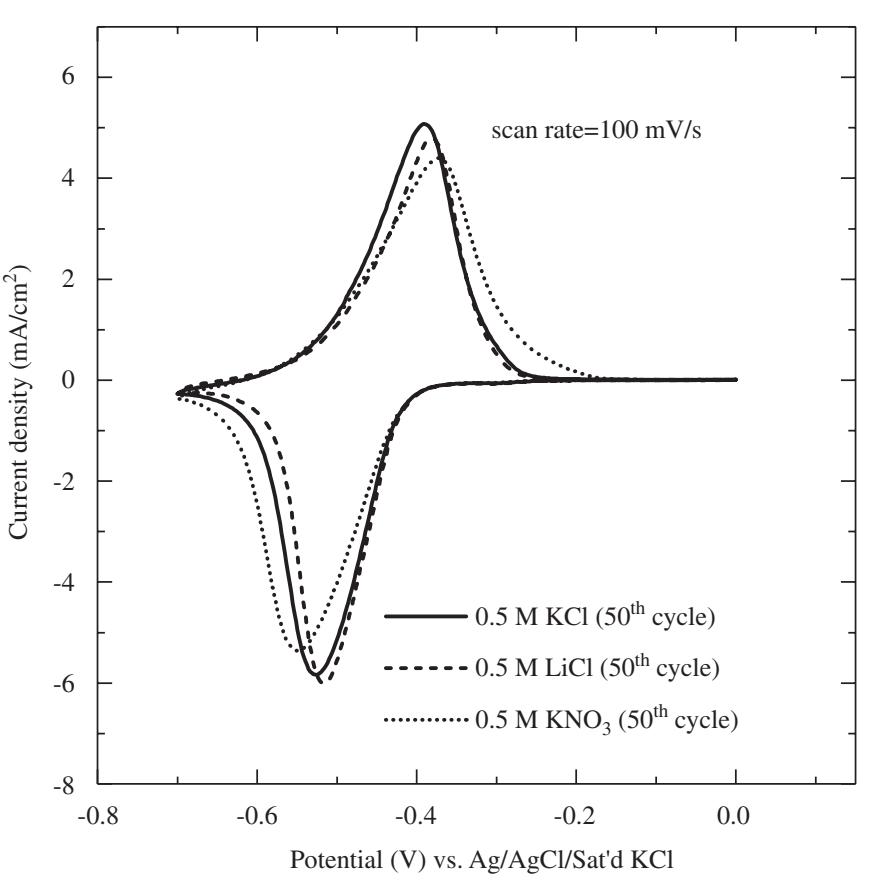

Fig. 4. Cyclic voltammograms at the 50th cycle of PBV films in $0.5 \mathrm{M} \mathrm{KCl}$ $(-), \mathrm{LiCl}(-\ldots)$, and $\mathrm{KNO}_{3}(\ldots \ldots)$ solution at a scan rate of $100 \mathrm{mV} / \mathrm{s}$.

harder to diffuse through the PBV film. This allows us to characterize specific resistance for various anions during the $\mathrm{PBV}^{2+} / \mathrm{PBV}^{\bullet+}$ redox reaction according to the anionic size.

\subsection{Ion transport phenomena}

EQCM technique can be a convenient method to analyze in situ ion transport within a polymer film during electrochemical cycling. The transports of cations, anions, and solvent, coming either from the bulk electrolyte or the polymer film, result in the measured mass changes [18], and the mass balance can be written as

$$
\Delta m_{(E)}=W_{\mathrm{C}}^{+} n_{\mathrm{C}(E)}^{+}+W_{\mathrm{A}}^{-} n_{\mathrm{A}(E)}^{-}+W_{\mathrm{S}} n_{\mathrm{S}(E)},
$$

where $\Delta m_{(E)}$ represents the mass change under a specific applied potential, $W_{\mathrm{C}}^{+}, W_{\mathrm{A}}^{-}$, and $W_{\mathrm{s}}$ are, respectively, the molar masses of the cation, anion, and solvent. $n_{\mathrm{C}(E)}^{+}, n_{\mathrm{A}(E)}^{-}$, and $n_{s(\mathrm{E})}$ are the amounts of substances (cation, anion, and solvent) during redox reaction (in mol). In addition to the mass conservation, the electroneutrality condition has to be satisfied for an electrochemical reaction. With this requirement, the accumulative charge passed at any potential $\left(\Delta Q_{(E)}\right)$ should be equal to the charge contributed from the ions, namely, the charge balance equation can be written as

$\Delta Q_{(E)}=z_{\mathrm{A}}^{-} F n_{\mathrm{A}(E)}^{-}-z_{\mathrm{C}}^{+} F n_{\mathrm{C}(E)}^{+}$

where $z_{\mathrm{A}}^{-}$and $z_{\mathrm{C}}^{+}$are the absolute values of the charge number of anion and cation, respectively, and $F$ is the Faraday constant. From Eqs. (3) and (4), one can obtain a

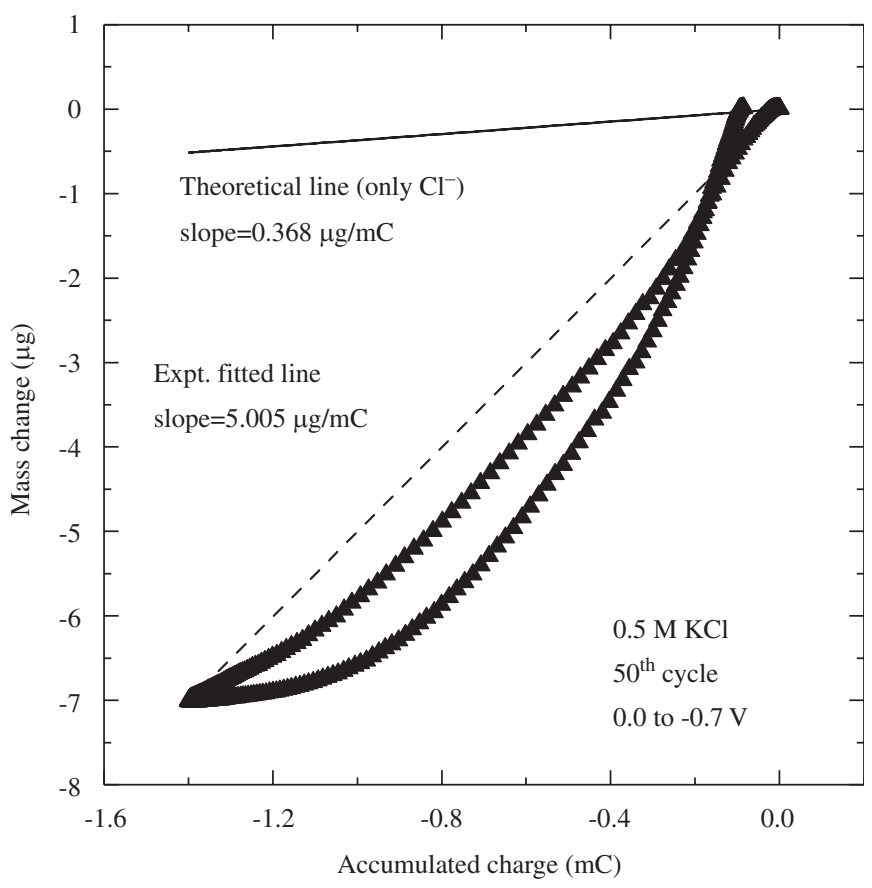

b

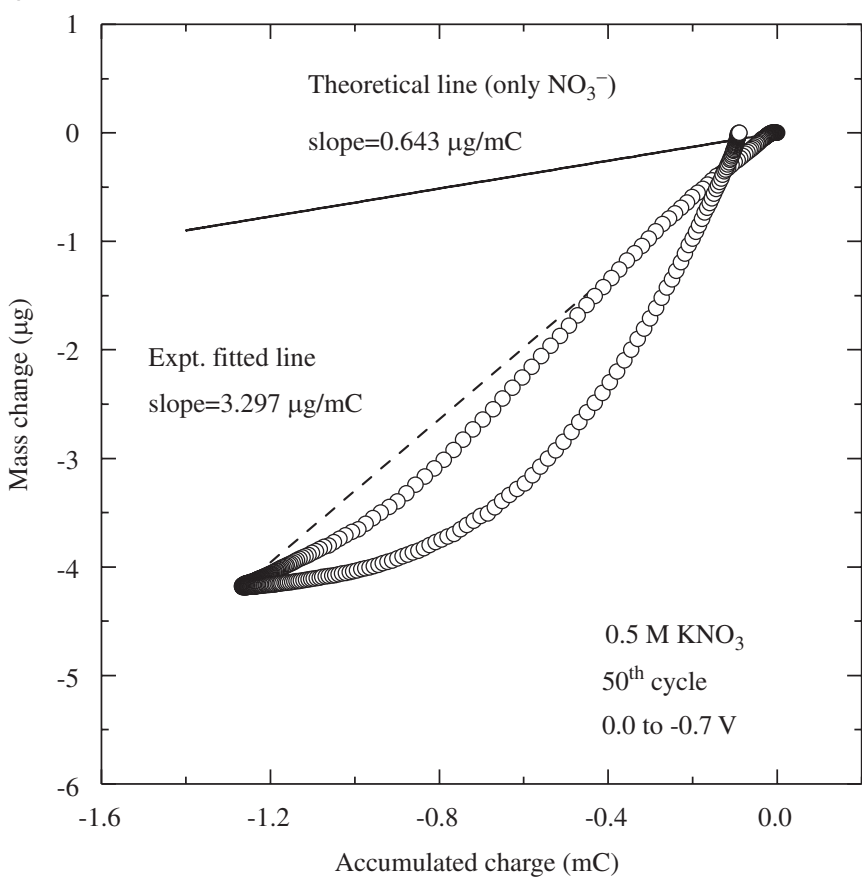

Fig. 5. The mass-charge relationship for PBV films in aqueous solution for (a) $0.5 \mathrm{M} \mathrm{KCl}$ with theoretical line of $\mathrm{Cl}^{-}$(-), experimental fitted line (- - -), and the measured dots points $(\mathbf{\Delta})$ and (b) $0.5 \mathrm{M} \mathrm{KNO}_{3}$ with theoretical line of $\mathrm{NO}_{3}^{-}(-)$, experimental line $(-\cdots)$, and the measured points $(\bigcirc)$.

the inserted or extractive amounts of ions and solvent molecules to better understand their transport phenomena.

Fig. 5(a) and 5(b) show the mass change vs. accumulated charge data for PBV films tested in the electrolytes of $\mathrm{KCl}$ and $\mathrm{KNO}_{3}$, respectively, which are selected from Fig. 3 . The theoretical values of the slope can be found from the 
following equation:

$\frac{\Delta m}{\Delta Q}=\frac{W_{\mathrm{A}}^{-}}{F}+\left(\frac{n_{\mathrm{S}}}{n_{\mathrm{A}}^{-}}\right) \frac{W_{\mathrm{S}}}{F}$.

Eq. (5) is obtained by dividing Eq. (3) by Eq. (4), in which the cationic terms were neglected and the value of $z_{\mathrm{A}}^{-}$was considered as unity in this work. Therefore, if only anion insertion or extraction is concerned, i.e., neglect the solvent term, one can obtain the theoretical slopes for $\mathrm{Cl}^{-}$and $\mathrm{NO}_{3}^{-}$, which are indicated by the straight solid lines, as shown in Fig. 5(a) and (b), respectively. The experimental dashed lines were fitted between the initial and the turning data points with intent to describe the mass change vs. accumulated charge for a whole oxidation or reduction process. The slopes of the theoretical line were smaller than that of the experimental fitted dashed lines for both $\mathrm{Cl}^{-}$

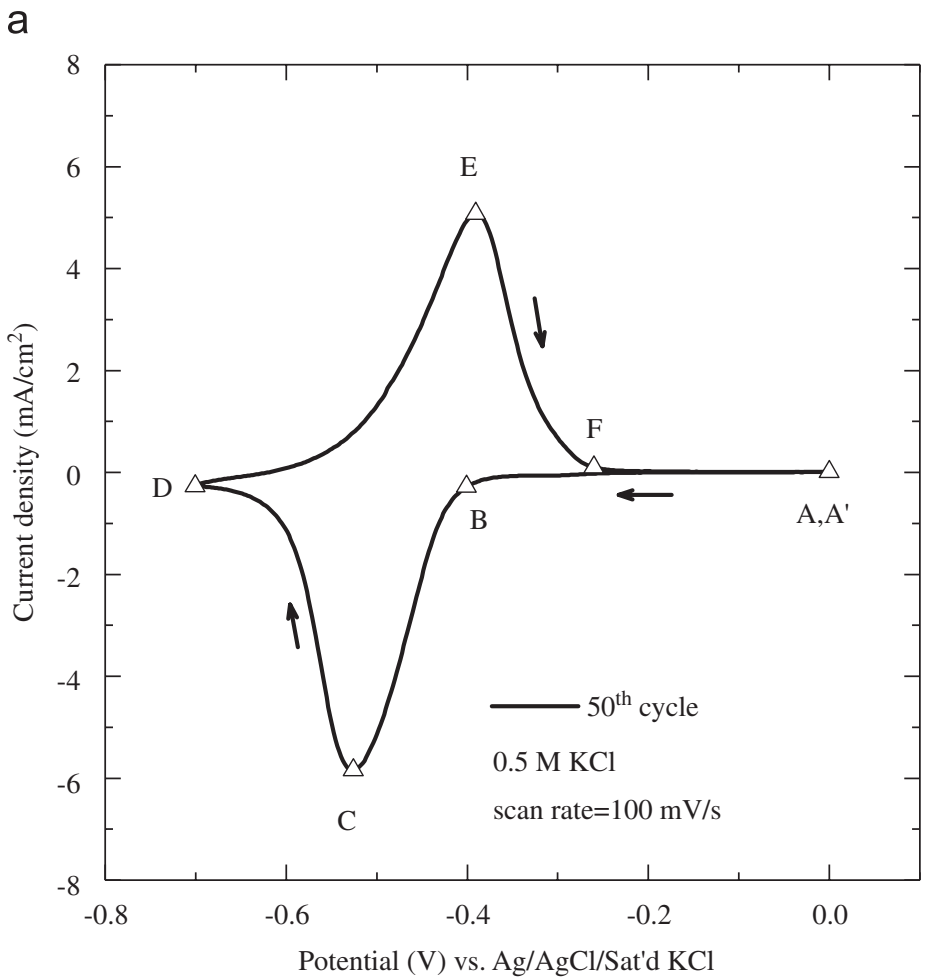

b

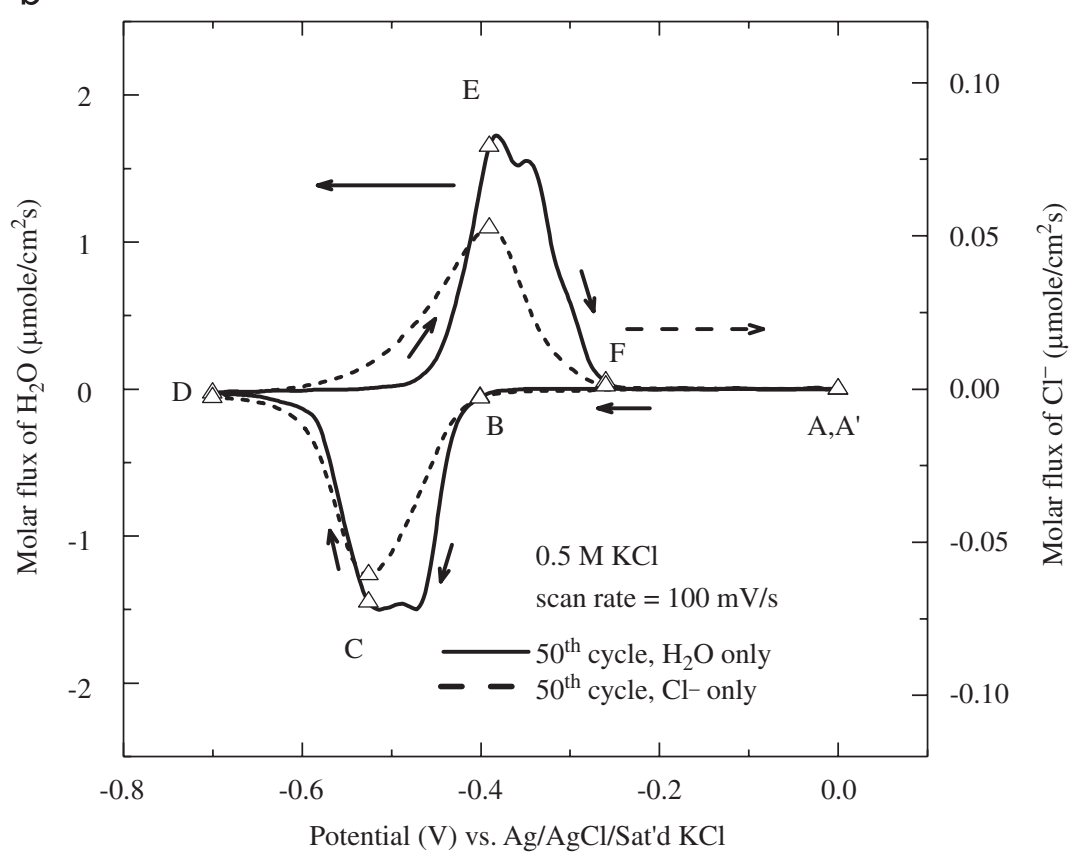

Fig. 6. (a) Cyclic voltammogram of a PBV film and (b) the corresponding molar fluxes of water (- -$)$ and $\mathrm{Cl}^{-}\left(--\Delta^{--}\right)$within the film in a $0.5 \mathrm{M} \mathrm{KCl}$ solution at the 50th redox scanning (scan rate $=100 \mathrm{mV} / \mathrm{s}$ ). 
and $\mathrm{NO}_{3}^{-}$. This indicates that both anions and solvent molecules, i.e., water, are involved in the transport during redox process. In fact, it was found that water molecules do transport in and out of the viologen monolayer during redox reaction $[7,8]$. Furthermore, the average number of accompanying water per anion, $n_{\mathrm{s}} / n_{\mathrm{A}}^{-}$, can be obtained by substituting the slope value into Eq. (5) to obtain 24.8 and 14.2 upon redox scanning in $\mathrm{KCl}$ and $\mathrm{KNO}_{3}$, respectively. Large amounts of accompanying water are resulted from the hydrophilic nature of $\mathrm{Cl}^{-}$and $\mathrm{NO}_{3}^{-}$, as compared to that of $\mathrm{ClO}_{4}^{-}$[7]. Accordingly, the average number of accompanying water per anion depends on the kind of anion itself, which implies that the interaction between PBV molecules and anions also determines the average water accompanied as well as the diffusion resistance of anions encountered as discussed in Section 3.2.

In addition to the average accompanying water molecules transferred per anion during the whole oxidation or reduction process, the molar fluxes of anion and water can be derived from Eqs. (3) and (4), and put in the following

a

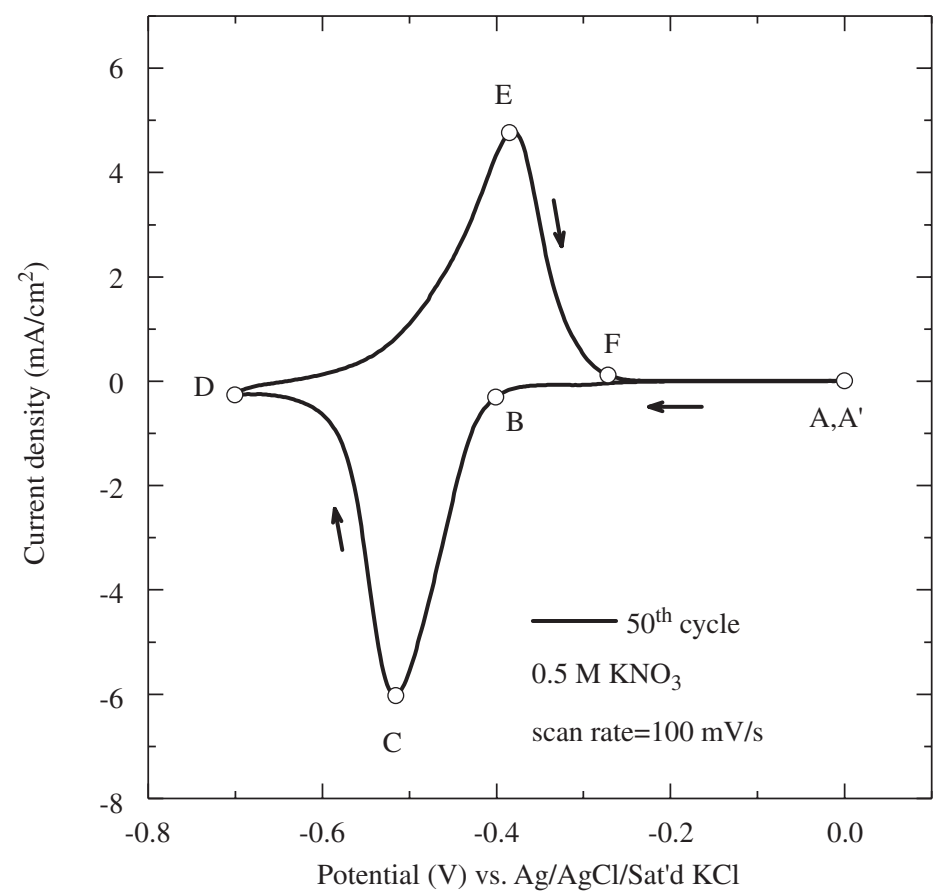

b

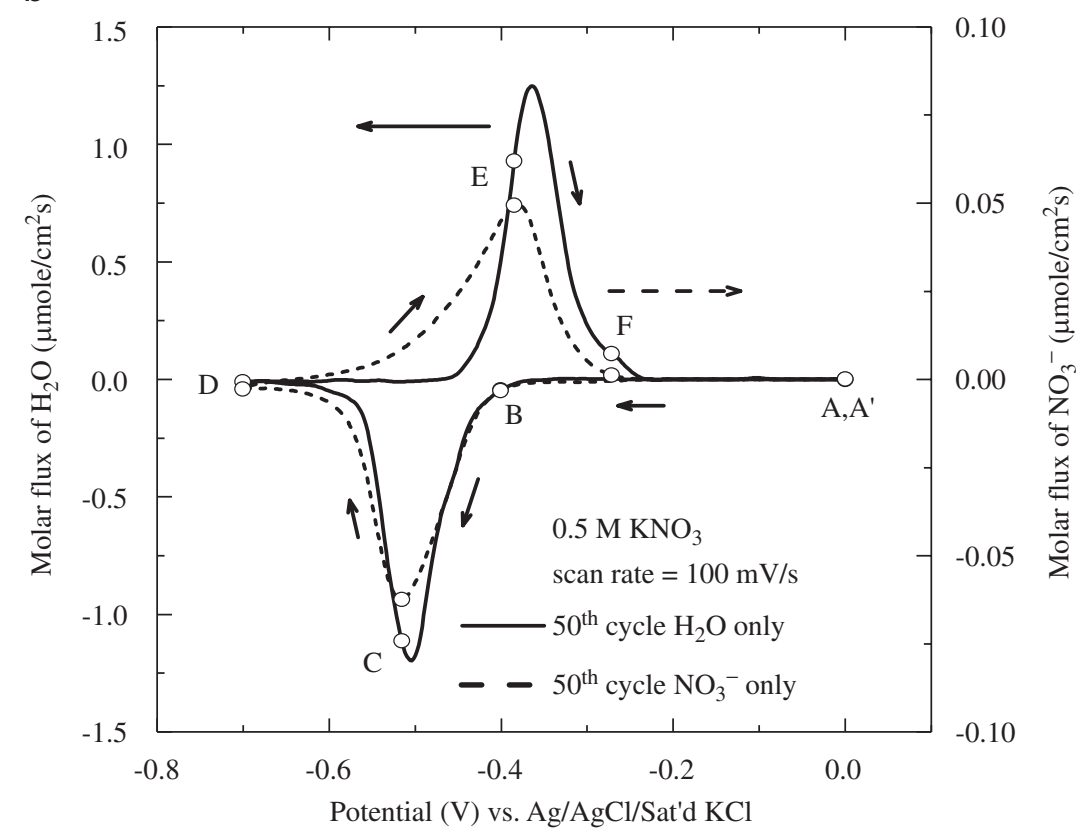

Fig. 7. (a) Cyclic voltammogram of a PBV film and (b) the corresponding molar fluxes of water (-O- ) and $\mathrm{NO}_{3}^{-}\left(--_{--} \mathrm{O}_{-}\right)$within the film in a $0.5 \mathrm{M}$ $\mathrm{KNO}_{3}$ solution at the 50 th redox scanning (scan rate $=100 \mathrm{mV} / \mathrm{s}$ ). 
equations:

$\frac{\mathrm{d} n_{\mathrm{A}(E)}^{-}}{A \mathrm{~d} t}=\frac{1}{A F} \frac{\mathrm{d}\left(\Delta Q_{(E)}\right)}{\mathrm{d} t}$,

$\frac{\mathrm{d} n_{\mathrm{S}(E)}}{A \mathrm{~d} t}=\frac{1}{W_{\mathrm{S}}} \frac{\mathrm{d}\left(\Delta m_{(E)}\right)}{A \mathrm{~d} t}-\frac{W_{\mathrm{A}}^{-}}{W_{\mathrm{S}}} \frac{\mathrm{d}\left(\Delta Q_{(E)}\right)}{A F \mathrm{~d} t}$.

The molar flux is defined as the number of mole of substances passed per unit area per unit time. However, the differentiation of $\Delta m$ with respect to time gave the scattered data, which are hard to average the characteristics of the flux. A Savitzky and Golay smooth method [19] was employed and the calculated molar fluxes during the first redox cycling of PBV films were obtained for the systems $\mathrm{Cl}^{-} /$water (Fig. 6(b)) and $\mathrm{NO}_{3}^{-} /$water (Fig. 7(b)). The alphabets labeled in Figs. 6 and 7 allow one to trace the transport behavior of anions and water molecules. For a PBV thin film switched in an aqueous solution containing $\mathrm{Cl}^{-}$, there was no signal for the current response (Fig. 6(a)) as well as the molar fluxes of $\mathrm{Cl}^{-}$and water (Fig. 6(b)) from point $\mathrm{A}$ to $\mathrm{B}$. This indicates that the reaction has not started yet. As the reduction began, the reduction current rose at point $\mathrm{B}, \mathrm{Cl}^{-}$along with the accompanying water started to be extracted out of the film and reached a maximum value at point $C$. From point $C$ to $D$, the reduction process gradually finished. In contrast to the reduction, the oxidation process from point $\mathrm{D}$ to $\mathrm{E}$ to $\mathrm{F}$ proceeded by the reverse reaction with the insertions of $\mathrm{Cl}^{-}$ and water. Moreover, for a PBV film switched in the $\mathrm{KNO}_{3}$ aqueous solution as shown in Fig. 7, the characteristics of the current density and the molar fluxes of $\mathrm{NO}_{3}^{-}$were almost the same as those of $\mathrm{Cl}^{-}$, except the number of accompanying water per anion. On the basis of these data, it appears that both $\mathrm{Cl}^{-}$and $\mathrm{NO}_{3}^{-}$were extracted out of the PBV film upon reduction and were inserted into the film upon oxidation, with different numbers of accompanying water per anion.

The instantaneous water to anion molar ratios at any applied potential, as shown in Fig. 8, were also obtained through the Savitzky and Golay smooth method by neglecting the difficult-to-smooth, near-zero part. From the results, one can determine the number of accompanying water molecule per $\mathrm{Cl}^{-}$or $\mathrm{NO}_{3}^{-}$at any potential during the first redox process. However, it is noted that, for both $\mathrm{Cl}^{-}$(Fig. 8(a)) and $\mathrm{NO}_{3}^{-}$(Fig. 8(b)), the molar flux ratios of water to anion during the oxidation process were higher than that of the reduction. By inspecting Figs. 6(b) and 7(b), the molar fluxes of both anions were not in phase with those of accompanying water during the oxidation process. Therefore, one can explain the sharp peaks of the reversing oxidation process for each anion, which were noticed in Fig. 8. For example, one observes in Fig. 6(b) that the molar flux of $\mathrm{Cl}^{-}$almost approaches zero at ca. $-0.3 \mathrm{~V}$ (the peak potential observed from Fig. 8(a)), while the flux of water is still large comparing to zero. For the film scanned in a $\mathrm{NO}_{3}^{-}$containing solution, as shown in Fig. 7(b), this situation is even more obvious at its peak potential which is a

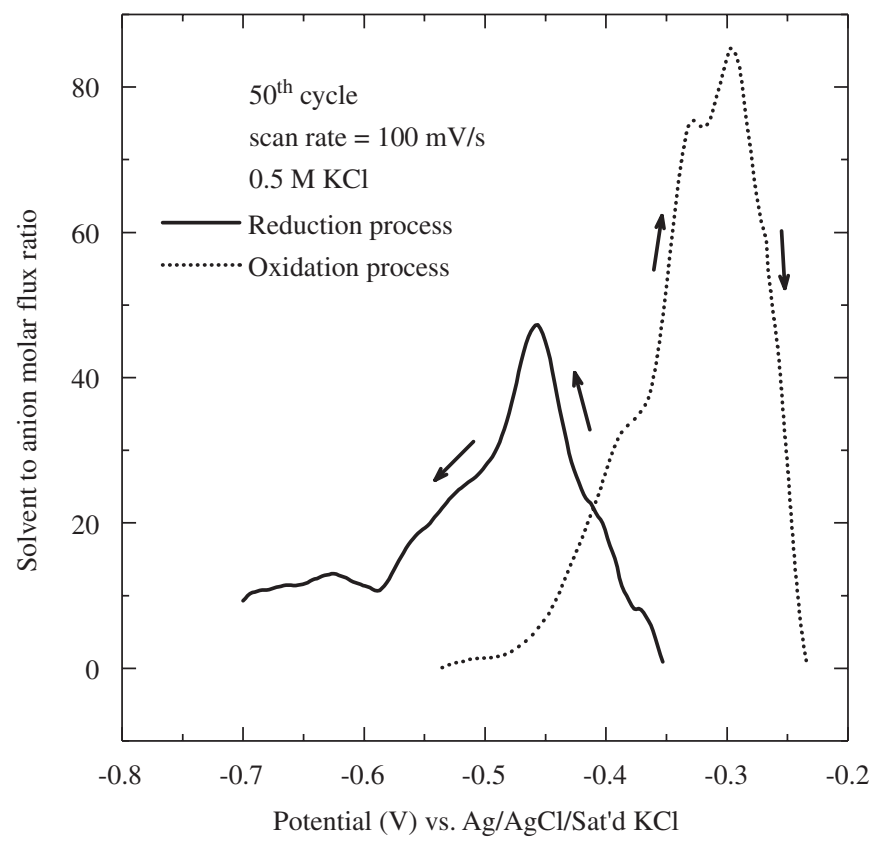

b

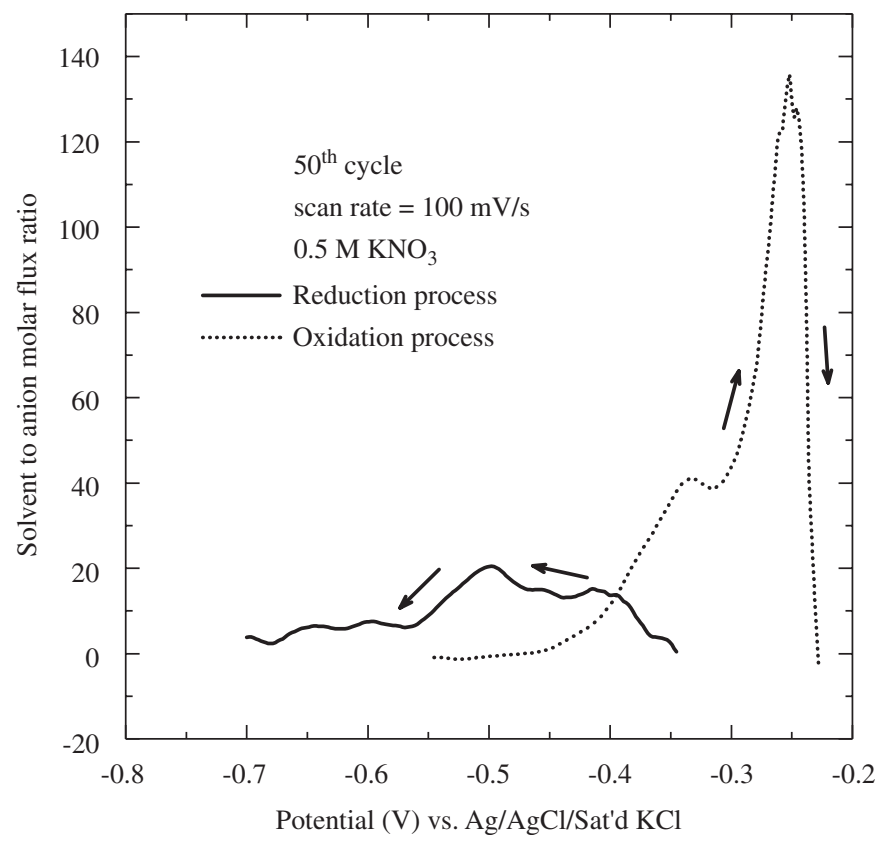

Fig. 8. The instantaneous water to (a) $\mathrm{Cl}^{-}$and (b) $\mathrm{NO}_{3}^{-}$molar ratio as a function of the applied potential at the 50 th $\mathrm{CV}$ cycling.

ca. $-0.26 \mathrm{~V}$, as seen from Fig. 8(b). This explains the reason why the solvent to anion molar flux ratios are so large, thus forming sharp peaks during the oxidation process as shown in Fig. 8 for both the $\mathrm{KNO}_{3}$ and $\mathrm{KCl}$ containing solutions. It is also the reason why these ratios during the oxidation process in the $\mathrm{NO}_{3}^{-}$containing solution are higher than those in the $\mathrm{Cl}^{-}$one. Since the anionic transport is driven by the electric field, while the water transport is governed by the diffusion process [20], it is expected that the transport of water would fall behind 
that of anion during the reversing scanning. In other word, the anion and water are in phase at the beginning of the reduction process, while the reversing bias exerts a strong electrical force on anion but not water. Therefore, a larger molar flux ratio of water to anion for the reversing oxidation is resulted from the lagged responses of water molecules. It is suggested that one can improve the simultaneity by selecting the scan rate.

\section{Conclusions}

The EQCM study of PBV films in aqueous solution containing different anions reveals an ion exchange process, which involves the transport of anion and solvent. For a PBV film with the residual ferrocyanides, the polycationic characteristics enable residual ferrocyanides being captured within the film. As long as there is a driving force, electrical field in this case, applies to the film and there are also other smaller anions exist in the bulk solution, the ion exchange process proceeds. In this work, the exchange process was complete around $50 \mathrm{CV}$ scans within the potential range of $\mathrm{PBV}^{2+} / \mathrm{PBV}^{\bullet+}$. After that, the ionic transport reached a steady state, making the intrinsic transport observation easier. Nevertheless, no significant cation transport was found as far as the mass change and the current response are concerned. The size of anion also affected its diffusion resistance through PBV films and resulted in different $\mathrm{PBV}^{2+} / \mathrm{PBV}^{\bullet+}$ redox behaviors. The study on the transports of anion and water suggested that both species exited the film upon reduction from $\mathrm{PBV}^{2+}$ to $\mathrm{PBV}^{\bullet+}$, and entered the film upon oxidation. The instantaneous water to anion molar ratios for $\mathrm{Cl}^{-}$and $\mathrm{NO}_{3}^{-}$involving the $\mathrm{PBV}^{2+} / \mathrm{PBV}^{\bullet+}$ redox reaction were obtained and the average accompanying water molecules were calculated to be about 24.8 per $\mathrm{Cl}^{-}$ and 14.2 per $\mathrm{NO}_{3}^{-}$due to their hydrophilic property. Furthermore, the molar fluxes of $\mathrm{Cl}^{-}$and $\mathrm{NO}_{3}^{-}$, as well as that of water, at any applied potential were quantified. Besides, a high scan rate results in a lagged response for water during the reversing oxidation process which leads to the formation of sharp peak. The transport behaviors of $\mathrm{Cl}^{-}$and $\mathrm{NO}_{3}^{-}$were almost the same except the number of accompanying water molecule.

\section{Acknowledgement}

The financial support provided by the National Science Council of Taiwan, ROC, under grant numbers NSC 952221-E-002-353-MY2 and NSC 96-ET-7-002-008-ET, is gratefully acknowledged.

\section{References}

[1] T. Saika, T. Iyoda, T. Shimidzu, Bull. Chem. Soc. Jpn. 66 (1993) 2054.

[2] K. Kamata, T. Suzuki, T. Kawai, T. Iyoda, J. Electroanal. Chem. 473 (1999) 145.

[3] Y.-C. Hsu, K.-C. Ho, J. New Mat. Electrochem. Syst. 8 (2005) 49.

[4] R.J. Mortimer, A.L. Dyer, J.R. Reynolds, Displays 27 (2006) 2.

[5] Q. Feng, W. Yue, T.M. Cotton, J. Phys. Chem. 94 (1990) 2082.

[6] D.A. Buttry, M.D. Ward, Chem. Rev. 92 (1992) 1355.

[7] H.C. De Long, D.A. Buttry, Langmuir 6 (1990) 1319.

[8] H.C. De Long, D.A. Buttry, Langmuir 8 (1992) 2491.

[9] S.A. John, T. Ohsaka, J. Electroanal. Chem. 477 (1999) 52.

[10] J.Y. Ock, H.K. Shin, D.J. Qian, J. Miyake, Y.S. Kwon, Jpn. J. Appl. Phys. 43 (2004) 2376.

[11] M.A. Vorotyntsev, E. Vieil, J. Heinze, J. Electroanal. Chem. 450 (1998) 121.

[12] C. Weidlich, K.-M. Mangold, K. Jüttner, Electrochim Acta 50 (2005) 1547.

[13] P.M.S. Monk, The Viologens: Physicochemical Properties, Synthesis and Applications of the Salts of 4,4'-Bipyridine, Wiley, New York, NY, 1998 Chapter 1.

[14] E.R. Nightingale, J. Phys. Chem. 63 (1959) 1381.

[15] G. Sauerbrey, Z. Phys. 155 (1959) 206.

[16] T. Komura, T. Yamaguchi, K. Furuta, K. Sirono, J. Electroanal. Chem. 534 (2002) 123.

[17] T. Sagara, H. Maeda, Y. Yuan, N. Nakashima, Langmuir 15 (1999) 3823.

[18] S.L. de Albuquerque Maranhão, R.M. Torresi, J. Electrochem. Soc. 146 (1999) 4179.

[19] A. Savitzky, M.J.E. Golay, Anal. Chem. 36 (1964) 1627.

[20] A.R. Hillman, Solid State Ionics 94 (1997) 151. 